\title{
An Integrated Motive Based Consumer Segmentation for Karaoke TV (KTV) and Service Strategy
}

\author{
Jiun-Hung Lin \\ Department of Marketing and Logistics Management, China University of Technology, Hukou Township, Taipei, \\ Chinese Taipei \\ Email: linjinghung.tem89g@nctu.edu.tw, jiun.hunglin@msa.hinet.net
}

Received 1 May 2015; accepted 7 July 2015; published 14 July 2015

\begin{abstract}
Motivation is the drive of an individual behavior and is highly related to what people talk and behave while Segmentation is an important marketing concept for business to understand the demand of consumer and formulate marketing strategy to fulfill consumer demand. An integrated model is developed in this research to segment Karaoke TV (KTV) consumer based on both their positive and negative motivations simultaneously with empirical data. Four segments are recognized as "Not fond of KTV group (6\%)", "Having slightly bad KTV experience with low self-confidence to singing group (29\%)", "Having bad KTV experience with slightly self-confidence to singing (47\%)", and "Social oriented singing star (18\%)". Service strategy is further explored for each segment.
\end{abstract}

\section{Keywords}

\section{Market Segmention, Motivation, Karaoke TV (KTV)}

\section{Introduction}

Segmentation is an important marketing concept for business to understand the demand of consumer and formulate marketing strategy. In today's busy and modern life, singing is an important recreation activity to help alleviate pressure. Hence, since 1990, Karaoke television-set (KTV) which is a form of interactive musical entertainment service has provided independent private room and interactive musical facilities for consumers to sing songs with friends or family is an important recreation activity in Taiwan [1] [2]. KTV service as a kind of recreation activities but is not free faces a keener competition because the recreation activities are more and more diversified and local government constructs many green and free public parks and places with holding many festival and activities to attract people to participate and consume [3] [4], so how to segment KTV consumer and establish service strategy to help expand the market and revenue is an important issue.

Past researches indicate that motivation to drive consumer to KTV consumption is complicated. Both positive motivation and negative motivation coexisted and would influence the consumption behavior of consumers to 
KTV [3] [4]. Therefore, how to segment KTV consumers based on their positive and negative motivation simultaneously and establish service strategy to attract consumer and content their need to help expand the market and revenue is an important issue to be studied.

\section{Theoretical Background}

\subsection{Karaoke TV (KTV)}

Karaoke television-set (KTV) means Karaoke with television-set. The origin of Karaoke television-set (KTV) is Karaoke comes from Japan [2]. Karaoke is singing in a public stage with the accompaniment of an orchestra without anybody. In the early 1980, Karaoke is introduced to Taiwan. However, Karaoke need consumer with courage to sing in the public but not the case for everyone. Hence, the .popularity of Karaoke is limited [5]. Karaoke was combined with a television-set in an independent and private room by business in Taiwan and developed a new type of recreation service called Karaoke television-set (KTV) in the early 1990 [2].

For consumer, KTV service is a place provides an independent and private room for consumer to sing with a vocal accompaniment video tape broadcasted on a larger television and stereo facility. Beverage and meal is also provided for consumer [6].

The characteristics of the service itself that would attract consumer such as having special atmosphere, exciting facilities, or convenient location are commonly positive motivations and are the pull power for recreations activities [5] [6]. For KTV consumption, previous studies recognized "Nice general services setting and quality", "Located in urban flourishing business district," "Wonderful singing related facilities," and "Located in recreation and entertainment district." as four pull power of KTV service [3] [4].

\subsection{Motivation of Karaoke TV (KTV) Consumption}

In psychology field, motivation is the drive of an individual behavior. Moreover, motivation is highly related to what people talk and behave. Motivation is the drive of an individual behavior [7]. There are positive and negative motivations that can induce individual behavior reaction [7]-[9].

"Positive motivation" is an inner drive that would guide individual behavior while "negative motivation" would resist individual behavior [7] [8]. Positive motivation induced by need, active personality learning or past bad experience while negative motivations induced by past bad experience, knowledge, shy personality, or poor personal ability are internal psychological obstacles that will resist consumer to do leisure activity.

KTV is a "heterologous space for experiencing imagination" and "the great decoration of the independent and private room [10]." The living room like design of the KTV room provides a place for consumer to have and share fun with friends. The KTV room is an isolated, safety, and private place and can make a small group abandon themselves to sing songs without any disturbance. The songs called for singing, the stars that perform the songs, and the vocal accompaniment video tape in the KTV room all can be the topic to talk and induce pleasant feeling of interpersonal relationship. Accordingly, the stateroom of KTV leads to stronger and closer interpersonal relationship among people in the room [10].

Previous researches proposed the motives drive consumer to KTV includes organizing a social party for family or friends, having flow across each other with family or friends, seeking for entertainment and exciting, escaping daily routine and forgetting trouble, practicing singing, relaxing stress, venting feeling or emotion, contenting the feeling to be a start [11]-[13]. Recently, KTV related recognized "Improve interpersonal relationship through self-expression by singing songs", "Entertainment", and "Organizing a social party", as three main positive motivations that would drive consumer to KTV [3].

Consumer may have internal psychological obstacles to go to KTV because of their past bad KTV consumption experience, shy personality, poor singing skill or knowledge and information about KTV service comes from media or friends. Therefore, there also exist negative motivations that would resist consumer to KTV. Previous researches proposed the negative motivations that would resist consumer to KTV include "Singing hardware and software is bad" and "Low self-confidence to singing in KTV" [4]. "Singing hardware and software is bad" is comes from past bad KTV consumption experience while "Low self-confidence to singing in KTV" is originated from personality or past experience.

Since motivation is the drive of an individual behavior and is highly related to what people talk and behave and both positive and negative motivations existed for consumer to KTV. The structure of motivations of KTV consumer is complicated. How to segment KTV consumer based on their positive and negative motivations and 
formulate service strategy is an important issue.

\section{Research Model and Methodology}

The first step of this research is segment KTV consumer by both positive and negative motivations. After recognize motivation based KTV consumer segmentations, based on the discussions in previous sections, this research develop hypothesis to be empirical tested as below to help formulate service strategy.

H1: KTV service characteristics are positively related to the positive motivation of consumer.

H2: KTV service characteristics are negatively related to the negative motivation of consumer.

KTV service characteristics, positive motivation of KTV consumer and negative motivation of KTV consumer are measured through measurement scales developed by previous studies [3] [4].

Likert seven point scale from very disagree to very agree is used to measure all items. All the questionnaires were answered by the KTV consumer in Taiwan.

Factor analysis is used to extract the factors of Pull power of KTV service and push power of internal demand. Hierarchical clustering was used to cluster individual by both positive motivation and negative motivation of KTV consumer. Regression is used to validate the assumptions developed to help formulate service strategy.

\section{Result}

Four hundred questionnaires were delivered and 261 valid questionnaires received, representing an effective response rate of $65 \%$.

Results of factor analysis indicated that KMO values of KTV service characteristics, positive motivation of KTV consumer and negative motivation of KTV consumer are all above 0.84 and Bartlett's Test of Sphericity for each construct is also significant at $\mathrm{p}$-value $<0.01$.

Four factors are extracted for KTV service characteristics and $67.8 \%$ of variance is extracted. Those factors are "V11: Nice general services setting and quality", "V12: Located in urban flourishing business district," "V13: Wonderful singing related facilities," and "V14: Located in recreation and entertainment district."

Three factors are extracted for positive motivation of KTV consumer and $61.2 \%$ of variance is extracted. Those factors are "V21: Improve interpersonal relationship through self-expression by singing songs," "V22: Entertainment," and "V23: Organizing a social party."

Two factors are extracted for negative motivation of KTV consumer and $63.2 \%$ of variance is extracted. These two factors are "V31: Singing hardware and software is bad" and "V32: Low self-confidence to singing in KTV."

Hierarchical clustering is used to segment KTV consumer based on their positive and negative motivations. Four segments are recognized as Figure 1 shows and are named as "Not fond of KTV group (6\%)," "Having slightly bad KTV experience with low self-confidence to singing group (29\%)," "Having bad KTV experience with slightly self-confidence to singing (47\%)," and "Social oriented singing star (18\%)."

The regression analysis result for each motivation segment indicates the standardized path coefficients and $R^{2}$ for each regression function in this study is presented in Figure 2.

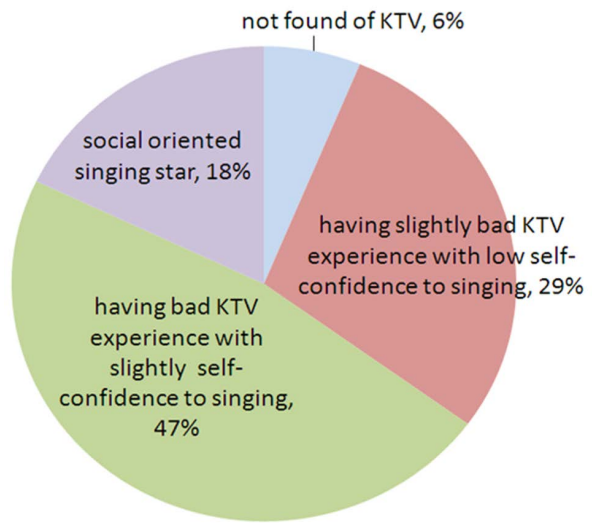

Figure 1. KTV segmentation. 


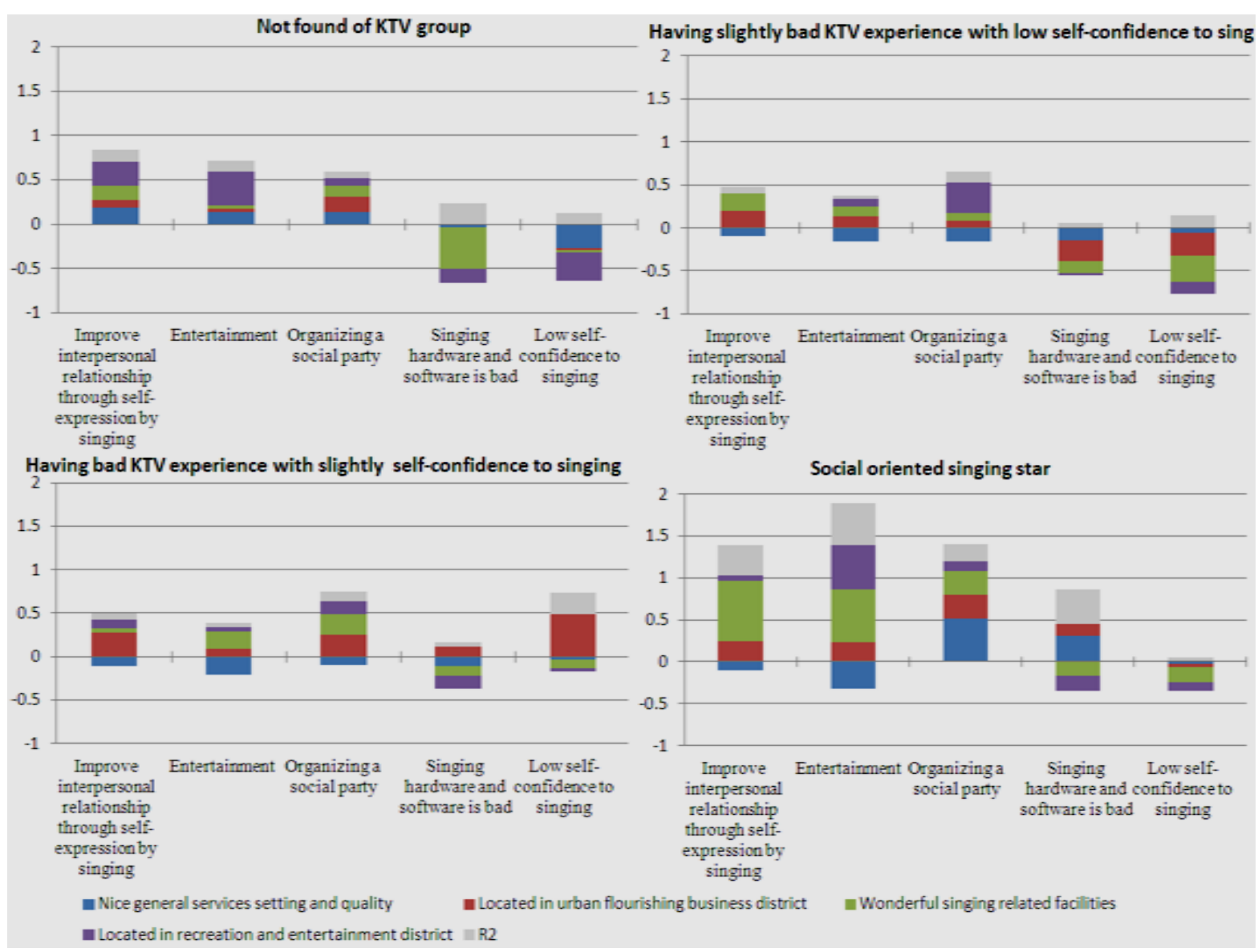

Figure 2. Regression analysis result for each motivation segments.

For "Not fond of KTV group (6\%)" The $R^{2}$ values for "Improve interpersonal relationship through self-expression by singing", "Entertainment", "Organizing a social party", "Singing hardware and software is bad", and "Low self-confidence to singing" are approaching $0.14,0.12,0.09,0.22$, and 0.12 , respectively. "Nice general services setting and quality" is only significantly negatively related to "Low self-confidence to singing". "Located in urban flourishing business district" is not significantly related to all five KTV motivations. "Wonderful singing related facilities" is only significantly negatively related to "Singing hardware and software is bad". "Located in recreation and entertainment district" is significantly positively related to "Improve interpersonal relationship through self-expression by singing" and "Entertainment" while it is significantly negative related to both "Singing hardware and software is bad" and "Low self-confidence to singing".

For "Having slightly bad KTV experience with low self-confidence to singing group (29\%)" The $R^{2}$ values for "Improve interpersonal relationship through self-expression by singing", "Entertainment", "Organizing a social party", "Singing hardware and software is bad", and "Low self-confidence to singing" are approaching 0.08 , $0.04,0.12,0.05$, and 0.15 , respectively. "Nice general services setting and quality" is not significantly related to all five KTV motivations. "Located in urban flourishing business district" is significantly negatively related to both "Singing hardware and software is bad" and "Low self-confidence to singing". "Wonderful singing related facilities" is only significantly negatively related to "Singing hardware and software is bad". "Located in recreation and entertainment district" is only significantly positively related to "Entertainment".

For "Having bad KTV experience with slightly self-confidence to singing (47\%)" The $R^{2}$ values for "Improve interpersonal relationship through self-expression by singing", "Entertainment", "Organizing a social party", "Singing hardware and software is bad", and "Low self-confidence to singing" are approaching 0.09, 0.06, 0.11, 0.04 , and 0.25 , respectively. "Nice general services setting and quality" is not significantly related to all five KTV motivations. "Located in urban flourishing business district" is significantly positively related to "Organizing a social party" and significantly negatively related to "Low self-confidence to singing". "Wonderful singing 
related facilities" is significantly positively related to "Organizing a social party" and significantly negatively related to "Singing hardware and software is bad" and "Low self-confidence to singing". "Located in recreation and entertainment district" is not significantly related to all five KTV motivations.

For "Social oriented singing star (18\%)" The $R^{2}$ values for "Improve interpersonal relationship through selfexpression by singing", "Entertainment", "Organizing a social party", "Singing hardware and software is bad", and "Low self-confidence to singing" are approaching $0.36,0.50,0.20,0.40$, and 0.05 , respectively. "Nice general services setting and quality" is significantly positively related to "Organizing a social party" and "Singing hardware and software is bad" while it is significantly negatively related to "Entertainment". "Located in urban flourishing business district" is significantly positively related to "Improve interpersonal relationship through self-expression by singing", "Organizing a social party" and "Singing hardware and software is bad". "Wonderful singing related facilities" is significantly positively related to "Entertainment" and significantly negatively related to "Singing hardware and software is bad". "Located in recreation and entertainment district" is significantly positively related to "Entertainment" and is significantly negatively related to "Singing hardware and software is bad".

\section{Conclusions}

According to the result of this research, the positive motivations of consumer to KTV would spur consumers to KTV while negative motivations of consumers to KTV would build obstacles to resist consumer to KTV. The pull power is induced by the KTV service itself. Three main positive motivations of consumer to KTV that are confirmed by this research are "Improve interpersonal relationship through self-expression by singing", "Entertainment" and "Organizing a social party". The two main internal psychological obstacles for consumer to KTV confirmed by this research are "Singing hardware and software is bad" and "Low self-confidence to singing". The pull powers induced by the service characteristics of the KTV itself are "nice general services setting and quality", "located in urban flourishing business district", "wonderful singing related facilities", and "located in recreation and entertainment district". Some of the pull power induced by the service itself would help increase positive motivations of consumers to KTV and decrease the internal psychological obstacles of consumers to KTV.

Based on consumer positive and negative motivations, four KTV consumer segments are recognized and are named as "Not fond of KTV group (6\%)", "Having slightly bad KTV experience with low self-confidence to singing group (29\%)", "Having bad KTV experience with slightly self-confidence to singing (47\%)", and "Social oriented singing star (18\%)".

For a consumer who is "Not fond of KTV", allocating KTV in recreation and entertainment districts with wonderful singing related facilities and nice general hardware and service outside the KTV room such as the lobby setting is good for them to eliminate their bad KTV consumption experience due to bad singing facilities and can make them have courage to singing in KTV and help improve interpersonal relationship and entertaining.

For "Having slightly bad KTV experience with low self-confidence to singing" consumers, allocating KTV in urban flourishing business districts with wonderful singing related facilities can help eliminate their bad KTV consumption experience due to bad singing facilities and can make them have courage to singing in KTV. While allocating KTV recreation and entertainment districts with wonderful singing related facilities can make them have courage to singing in KTV and help entertaining.

For "Having bad KTV experience with slightly self-confidence to singing (47\%)" consumers, allocating KTV in urban flourishing business districts with wonderful singing related facilities will help them to organize a social party and eliminate their bad KTV consumption experience due to bad singing facilities and can make them have courage to singing in KTV.

For "Social oriented singing star" consumers, allocating KTV in urban flourishing business districts with wonderful singing related facilities and nice general hardware and service outside the KTV room such as the lobby setting can help eliminate their bad KTV consumption experience due to bad singing facilities and is good for them to improve interpersonal relationship, entertaining and organizing a social party. Moreover, allocating KTV in recreation and entertainment districts with wonderful singing related facilities and nice general hardware and service outside the KTV room such as the lobby setting can help eliminate their bad KTV consumption experience due to bad singing facilities and is good for them to improve interpersonal relationship, entertaining 
and organizing a social party.

\section{References}

[1] Chiang, Y.Z. (2006) One Million Lonely Heart Wait for Happiness in the Three Metro City. Global Views Magazine, 238, 166-174.

[2] Sha, G.G. (1992) The Politic Economic of Recreation-The First Analysis to the KTV in Taiwan. Journal of Outdoor Recreation Study, 5, 145-163.

[3] Lin, J.H. (2013) The Effect of Pull Power of Karaoke Television-Set Service on the Inner Need of Consumer. iBusiness, 5, $52-54$

[4] Lin, J.H. (2014) The Effect of Pull Power of Karaoke Television-Set Service on Eliminating the Internal Psychological Obstacles of Consumer. Open Journal of Social Sciences, 2, 87-90. http://dx.doi.org/10.4236/jss.2014.29015

[5] Su, F.S. (2006) The Study of Motivations, Obstructions, and Health Effects of Teenage Students to Sing at KTV Stores. Unpublished Master Thesis of Department of Leisure and Recreation, Asia University, Taichung.

[6] DCAMEA [Department of Commercial Affairs of Ministry of Economic Affairs] (2000) The Change and Future Trend of Audio-Visual Entertainment Industry. Annual Report of Service Business in Taiwan, 21-46.

[7] Fodness, D. (2004) Measuring Tourist Motivation. Annals of Tourism Research, 21, 555-581.

[8] Gnoth, J. (1997) Tourism Motivation and Expectation Formation. Annals of Tourism Research, 24, 283-304. http://dx.doi.org/10.1016/S0160-7383(97)80002-3

[9] Chang, Z.S. (1990) Chang's Psychology Dictionary. Tunghua. Publish Ltd., Taipei.

[10] Zhang, S.M. (1993) Leisure, Pleasure, and Power-A Sociological Analysis of KTV in Taiwan. Unpublished Master Thesis of Graduate Institute of Building and Planning, National Taiwan University, Taipei, Taiwan.

[11] Su, F.S. (2006) The Study of Motivations, Obstructions, and Health Effects of Teenage Students to Sing at KTV Stores. Unpublished Master Thesis of Department of Leisure and Recreation, Asia University, Taichung.

[12] Cheng, T.L. (1993) The Study of KTV Consumer's Motives and Behaviors. Unpublished Master Thesis of Department of News, Chinese Cultural University, Taipei.

[13] Chen, Y.F. (2006) A Study of Key Determinants of Hedonic Experience in KTV Industry. Unpublished Master Thesis of Department of Marketing and Logistics, National Kaohsiung First University of Technology, Kaohsiung. 